\title{
Working
}

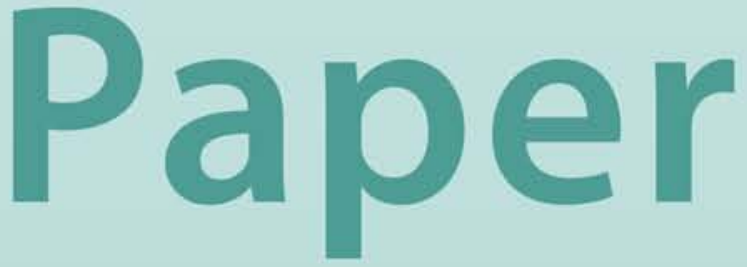


Injury Investigations in Anti-dumping and the Super-Additivity Effect: A Theoretical Explanation

Poonam Gupta and Arvind Panagariya 


\title{
IMF Working Paper
}

Asia and Pacific Department

\section{Injury Investigations in Anti-Dumping and the Super-Additivity Effect: A Theoretical Explanation}

\author{
Prepared by Poonam Gupta and Arvind Panagariya ${ }^{1}$ \\ Authorized for distribution by James Gordon
}

August 2001

\begin{tabular}{l} 
Abstract \\
$\begin{array}{l}\text { The views expressed in this Working Paper are those of the author(s) and do not necessarily } \\
\text { represent those of the IMF or IMF policy. Working Papers describe research in progress by the } \\
\text { author(s) and are published to elicit comments and to further debate. }\end{array}$ \\
\hline
\end{tabular}

Empirical evidence shows that injury investigations in anti-dumping cases conducted by the United States International Trade Commission, the probability of a positive finding is higher when the number of defendant firms is larger, holding constant their total market share. In this paper we offer a theoretical explanation of this finding. We show that the presence of many exporters exacerbates the free-rider problem, which leads every firm to invest less on defense. Thus for the same market share, injury finding is more likely to be positive for many small sellers than a few large sellers.

JEL Classification Numbers:F13, L13

Keywords: Anti-dumping, cumulation, injury investigation

Author's E-Mail Address:imf_india@vsnl.net; panagari@wam.umd.edu

\footnotetext{
${ }^{\mathrm{I}}$ Prof. Panagariya is at the University of Maryland, College Park, MD 20742. This paper was written while Prof. Panagariya was a Visiting Scholar at the Fund and while Ms. Gupta was an economist in the Fund's Research Department. Ms. Gupta is presently an economist at the Fund's office in New Delhi. The contents represent the views of the authors and authors alone. We are grateful to Bruce Blonigen, Jim Gordon, Tom Prusa, and Robert Staiger for comments on an earlier draft.
} 


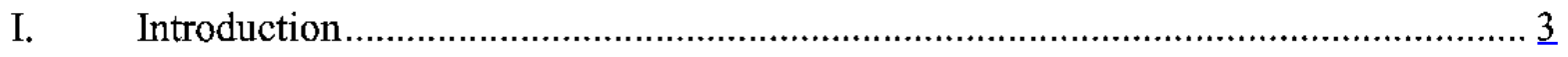

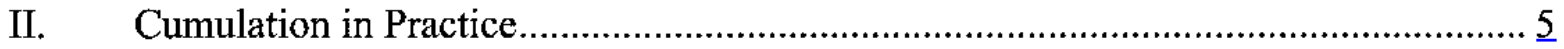

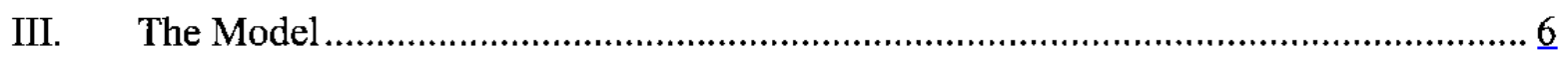

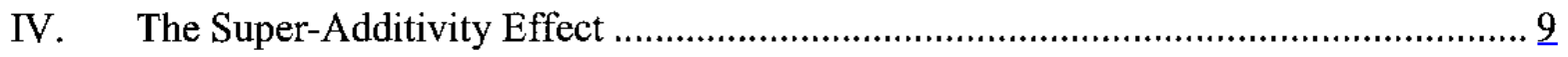

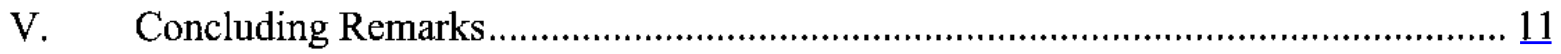

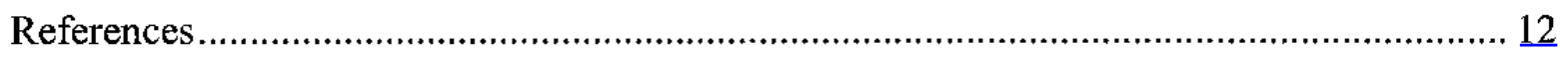




\section{INTRODUCTION}

Successful prosecution in anti-dumping cases involves two separate steps: establishing injury to the domestic industry from increased imports and determining a positive dumping margin. The latter is typically measured by the excess price charged by the defendant firm in its domestic market over what it charges in the market where dumping is said to have taken place. In the United States, the International Trade Commission does the injury investigation while the Department of Commerce determines the dumping margin.

In this paper, we offer a theoretical explanation of a surprising empirical finding relating to injury investigations in anti-dumping cases. In an important paper, Hansen and Prusa (1996) carry out a careful econometric investigation of the determinants of an affirmative finding in the injury investigations conducted by the United States International Trade Commission. Among other things, they find that the probability of a positive finding is higher when defendants are many and small than when they are few and large. Stated precisely, they find that, holding the market share of defendant firms constant, "cumulation," defined as the practice of aggregating over the exports of several countries, has a positive effect on the probability of an affirmative injury determination. A subsequent paper by Tharakan, Greenaway and Tharakan (1998) confirms this finding for the European Community injury decisions as well. ${ }^{2}$

That cumulation should raise the probability of a positive injury determination is not surprising: adding one more country to the set of countries investigated raises the market share of the accused firms and, ceteris paribus, must make the case for a positive finding stronger. The surprising aspect of the Hansen and Prusa (1996) and Tharakan, Greenaway and Tharakan (1998) studies is the presence of what the former call the "super-additivity" effect: for the same market share, cumulation raises the probability of affirmative injury determination. ${ }^{3}$ Interestingly, however, neither of these sets of authors provides any explanation-whether heuristic or formal--of this finding.

In this paper, we suggest one possible formal explanation why affirmative injury determination is more likely when defendants are many and small rather than a few and large. We show that the presence of many small exporters exacerbates the free-rider problem that accompanies multiple defendants. Unlike the dumping margin, which must be determined separately for each defendant firm, the injury determination is common to all defendant firms: either all defendants are found guilty of causing injury to the domestic firm

${ }^{2}$ The literature on anti-dumping, though still in its infancy, is growing rapidly. For example, see Anderson (1993), Blonigen and Haynes (1999), Ethier (1982), Panagariya and Gupta (1998), Rosendroff (1996), and Staiger and Wolak (1992, 1994).

${ }^{3}$ As Hansen and Prusa (1996) note, this outcome has encouraged domestic industries to file more cases against countries with smaller market shares. 
or all are acquitted. ${ }^{4}$ To the extent that defense may be costly, this fact inevitably gives rise to a free-rider problem. At one extreme, if a single large firm is subject to investigation, it has every incentive to defend itself. At the other extreme, if tens of small firms spread over as many countries are investigated, none may have an incentive to defend, giving the domestic, plaintiff firms a free hand in influencing the outcome. ${ }^{5}$

Our analysis is closely related to the vast body of literature on private provision of a public good. Among the directly relevant contributions are the papers by Rodrik (1986) and Panagariya and Rodrik (1993). ${ }^{6}$ Rodrik (1986) offers an argument why welfare-maximizing governments may choose tariffs over production subsidies in the presence of lobbying. When lobbying is at the level of the firm, since output subsidies can be firm specific, they do not pose a free-rider problem. But tariffs are levied industry wide so that there is a free-rider problem at the firm level. Therefore, the equilibrium tariff turns out to be smaller than the equilibrium level of subsidies and may be superior even though it distorts consumption. Similarly, Panagariya and Rodrik (1993) demonstrate why, under plausible conditions, the adoption of a uniform tariff rule may lead to a superior outcome. When lobbying for tariffs is at the level of the industry, the uniform-tariff rule creates a free-rider problem since the tariff granted to one industry is granted to all industries. This lowers the incentive for everyone to lobby.

In the present paper, the free-rider problem, leading to the super-additivity effect, arises in the provision of defense by the defendant firms against the injury charge. The defense provided by one firm becomes automatically available to all firms subject to the investigation. This leads every firm to invest less on defense than will be the case in a cooperative solution. Ceteris paribus, the larger the number of firms charged, the more serious the free-rider problem.

To our knowledge, this focus on the free-rider problem on the defendant side of the game for protection is new. Traditionally, the literature has focused on the free-rider problem on the side of petitioners. For instance, in Rodrik (1986) and Panagariya and Rodrik (1993) above, lobbies seeking tariffs or subsidies are effectively petitioners. Likewise, in antidumping cases, we may encounter free riding among petitioners since the domestic producers benefit from anti-dumping actions regardless of whether or not they contribute to the petition.

\footnotetext{
${ }^{4}$ In informal correspondence, a United States International Trade Commission official puts the matter as follows: "It is not possible to reach different determinations on imports from countries that have been cumulated. The only way to reach different determinations is not to cumulate."
}

${ }^{5}$ When there are fewer firms they may also be able to collude in defending themselves and thus avoid the free riding problem altogether.

${ }^{6}$ Also see Hillman (1989, chapter 6) and Ursprung (1990). 
Though our objective is limited and specific, we also provide a simple but general framework for the analysis of the injury issue. To-date, the theoretical literature on the injury issue is virtually nonexistent. Therefore, future empiricists as well as trade theorists interested in this issue will find our framework helpful. We begin in Section 2 with some institutional details and evidence on the increased role of cumulation in injury cases in recent years in the United States and European Union. Our formal model is then outlined in Section 3. Our main result is derived in Section 4. Our brief concluding remarks are provided in Section 5.

\section{Cumulation in Practice}

The cumulation amendment was enacted by the United States Congress in 1984, which requires the United States International Trade Commission (USITC) to cumulate imports when a trade dispute involves imports from multiple sources. The statute states, "The commission shall cumulatively assess the volume and effect of imports of the subject merchandise from all countries with respect to which petitions were filed or investigations were self-initiated on the same day, if such imports compete with each other and with domestic like products in the United States market."

Prior to 1984, the USITC had some discretion with respect to whether or not to cumulate the imports of different defendants in the determination of injury. But the 1984 amendment makes it mandatory to cumulate in cases involving multiple defendants. As Prusa (1998) documents, since the 1984 amendment, cumulation has been applied with much greater frequency. While only 13 percent of the anti-dumping cases were subject to cumulation between $1980-84$, as many as 75 percent became subject to this practice between 1985 and 1994. According to Tharakan, Greenaway and Tharakan (1998), cumulation has also been practiced liberally in the European Communities (EC). During 1980-87, 91 percent of the multiple-country filings were determined on the basis of the cumulated market share of imports.

Hansen and Prusa (1996) and Tharakan, Greenaway and Tharakan (1998) study the experience of the United States and EC, respectively, and show that holding the share of defendant firms in total sales constant, cumulation increases the probability of an affirmative injury determination. According to an example considered in Hansen and Prusa (1996), when 40 percent of imports are under investigation and a single country is involved, the probability of an affirmative injury finding is 0.60 . But when the petition is filed against two countries with a cumulated market share of 40 percent, divided equally between them, the probability rises to .72 . This change represents a 20 percent increase in the probability of affirmative action. Extending the example to five countries, holding constant the market share of imports, the probability rises to .78 or by 30 percent. Tharakan, Greenaway and Tharakan (1998) provide similar examples using the estimates for the EC. The probability of an affirmative finding rises from .92 for two countries to .98 for 3 countries, holding constant the market share of imports under investigation. Thus, cumulation has played a significant 
role in yielding a positive injury determination. Why has this been so? This key question is the subject matter for the rest of this paper.

\section{THE MODEL}

We work with a model in which there are three types of firms: firms from the country in which dumping takes place, exporting firms subject to the anti-dumping action, and other exporting firms. The product under consideration is homogeneous and the firms are assumed to engage in Cournot competition. We do not model the decision of domestic firms to bring the anti-dumping petition, nor do we formalize the process by which the firms charged with dumping are chosen. Our focus is on the choices made by defendant firms in the injury investigation.

Throughout, we denote the variables associated with the country in which dumping takes place by upper-case letters, those associated with the firms subject to the anti-dumping action by lower-case letters and those relating to other exporting firms by lower-case letters with an asterisk. To keep the analysis simple, we work with linear demand and linear production costs. Our central result does not depend in any way on these linearities, however. Thus, we write the inverse demand function facing the firms in the country where dumping takes place as:

$$
P=a-b X
$$

where $\mathrm{P}$ denotes the market price, $\mathrm{X}$ the total demand, and $\mathrm{a}$ and $\mathrm{b}$ are positive constants. The equality of demand and supply implies:

$$
X=\sum_{i} Q_{i}+\sum_{j} q_{j}+\sum_{r} q_{r}^{*}
$$

where $Q_{i}, q_{j}$ and $q_{r}{ }^{*}$ denote the outputs of ith, $j$ th and rth firms from the three sources. Assuming Cournot behavior, the profit maximization problem of a firm from the country where sales take place, say firm s, may be written:

$$
\operatorname{Max}_{\mathrm{Q}_{\mathrm{s}}} \mathrm{H} \quad \Gamma_{\mathrm{a}} \quad \mathrm{b}\left\{\sum_{\mathrm{i}} \mathrm{Q}_{\mathrm{i}} \quad \sum_{\mathrm{j}} \mathrm{q}_{\mathrm{j}} \quad \sum_{\mathrm{r}} \mathrm{q}^{*} \mathrm{C}_{\mathrm{s}}\right\rceil_{\mathrm{Q}_{\mathrm{s}}}
$$

where $\mathrm{C}_{\mathrm{s}}$ is the constant average and marginal cost of production of firm s. Assuming for simplicity that firms within each group are identical, we can drop subscript $\mathrm{s}$ and denote the solution to this problem by:

$$
\mathrm{Q}=\frac{\mathrm{P}-\mathrm{C}}{\mathrm{b}}
$$

Analogously, the solution to the profit maximization problem of a representative firm from the third countries is: 


$$
\mathrm{q}^{*}=\frac{\mathrm{P}-\mathrm{c}^{*}}{\mathrm{~b}}
$$

Note that this solution assumes that the group of exporting firms not subject to anti-dumping action is known before production decisions are made. Within the model, this property can be justified under the assumption that the profit-maximizing price of these firms in their home markets is lower than that in the market where dumping takes place. As such they know beforehand that they will not be subject to the dumping charge.

The firms also know beforehand that they will be charged with dumping. Again, this can be rationalized by assuming that the profit-maximizing price of these firms in their domestic market is higher than that in the market where dumping takes place. In addition, we assume that the presence of the dumping margin necessarily leads to anti-dumping and hence injury investigation. ${ }^{7}$ While the injury investigation is, thus, necessarily undertaken, there is uncertainty with respect to the final outcome and hence eventual prosecution. Under the current national laws, which must conform to the GATT Article VI and the WTO Agreement on anti-dumping, no anti-dumping duties can be levied without a positive determination of injury to the domestic industry.

We assume that the probability of a positive injury determination varies directly with the combined market share of the firms charged with dumping. ${ }^{8}$ As is generally true in practice, this means that either all firms are found guilty or all are acquitted. We further assume that the firms can invest resources to defend themselves against the injury charge. By assumption, the probability of a positive finding varies inversely with the total amount of resources so invested by the defending firms. Thus, the probability of a positive finding is written,

$$
\rho=\rho\left(\frac{\sum_{j} q_{j}}{X}, \sum_{j} e_{j}\right)
$$

\footnotetext{
${ }^{7}$ Implicitly, we model exporting firms as discriminating monopolists. A more sophisticated formalization would follow Brander and Krugman (1983).

${ }^{8}$ To determine injury in the United States, the law directs the USITC to consider the volume of imports of the subject merchandise, the effects of imports of that merchandise on prices in the United Sates for domestic like products, and the impact of imports of such merchandise on domestic producers of domestic like products in the context of production operations within the United States.
} 
where $e_{j}$ is the expenditure on defense incurred by firm $\mathrm{j}$. Based on the assumptions just outlined, $\rho_{1}()>$.0 and $\rho_{2}()<$.0 , where $\rho_{1}($.$) and \rho_{2}($.$) represent the partial derivatives of \rho($. with respect to first and second arguments, respectively. In addition, we impose the plausible restrictions $\rho_{11}<0$ and $\rho_{22}>0$. The former restriction says that the increase in the import share increases the probability of affirmative action at a diminishing rate. The latter restriction says that the marginal reduction in the probability of affirmative action attributable to the expenditure on defense declines as we increase the expenditure.

We assume that if the finding on injury is positive, each firm is subject to a fine that is equal to the difference between the price in the market under consideration and that in the firm's home market. Assuming the firms are risk neutral and therefore maximize expected profits, we can write the objective function of firm $\mathrm{k}$ as:

$$
\begin{aligned}
\underset{\mathrm{q}_{\mathrm{k}}, e_{\mathrm{k}}}{\operatorname{Max} \mathrm{h}}= & \rho(.)\left[\mathrm{a}-\mathrm{b}\left\{\sum_{\mathrm{i}} \mathrm{Q}_{\mathrm{i}}+\sum_{\mathrm{j}} \mathrm{q}_{\mathrm{j}}+\sum_{\mathrm{r}} \mathrm{q}_{\mathrm{r}}^{*}\right\}-\mathrm{c}_{\mathrm{k}}-\mathrm{f}_{\mathrm{k}}\right] \mathrm{q}_{\mathrm{k}} \\
& +[1-\rho(.)]\left[\mathrm{a}-\mathrm{b}\left\{\sum_{\mathrm{i}} \mathrm{Q}_{\mathrm{i}}+\sum_{\mathrm{j}} \mathrm{q}_{\mathrm{j}}+\sum_{\mathrm{r}} \mathrm{q}_{\mathrm{r}}^{*}\right\}-\mathrm{c}_{\mathrm{k}}\right] \mathrm{q}_{\mathrm{k}}-\mathrm{e}_{\mathrm{k}}
\end{aligned}
$$

where $f_{k}$ is the anti-dumping duty on firm $k, c_{k}$ its average and marginal cost of production and $e_{k}$ the expenditure on defense. ${ }^{9}$ After some simplifications and assuming symmetry, we can represent the first order conditions by:

$$
\begin{aligned}
& h_{q}=-\rho_{1}(\beta, \text { ne }) f \frac{\beta(1-\beta)}{n}-f \rho(.)+(P-b q)-c=0 \\
& h_{e}=-\rho_{2}(\beta, \text { ne) } f q-1=0
\end{aligned}
$$

where we have set $\beta \equiv \mathrm{nq} / \mathrm{X}$, the market share of the firms charged with dumping. Also, taking advantage of the symmetry, we have set $\sum \mathrm{e}_{\mathrm{j}}=$ ne.

\footnotetext{
${ }^{9}$ In practice, fine $\mathrm{f}_{\mathrm{k}}$ equals the dumping margin, which is calculated as the difference between the firm's price in its own domestic market and the market in which dumping takes place. Incorporating this feature into the analysis requires the introduction of the firm's domestic market explicitly, which introduces complications that are not central to our analysis. Instead, assuming the firm's price in its own domestic market (not modeled) to be constant at $\mathrm{P}^{* *}$, we can replace $\mathrm{f}_{\mathrm{k}}$ by $\mathrm{P}^{* *}$-P and still obtain our central result. Alternatively, as Bruce Blonigen has suggested to us, we could assume that the "fair value" used in the dumping margin is a constructed cost measure which is fixed. The Department of Commerce uses the constructed cost method in a significant number of cases.
} 
According to (8), the expected marginal revenue must be set equal to the marginal cost of production. The first term on the left-hand side of this equation is the reduction in the revenue due to increased probability of a positive finding and hence increased expected fine on the existing quantity sold. The second term in the same equation is the expected fine on the extra unit produced and the third term the extra revenue generated by the sales of another unit of the product. According to (9), the marginal revenue from increased effort by the firm to counter the dumping charge is equated to the marginal cost. The first term in this equation is the reduction in the fine attributable to a unit increase in the expenditure to combat dumping, while the second term is the cost of a unit increase in this effort.

Given our symmetry assumptions, we can rewrite equation (2) as:

$$
\mathrm{X}=\mathrm{NQ}+\mathrm{n}^{*} \mathrm{q}^{*}+\mathrm{nq}
$$

Equations (1), (2'), (4)-(6), (8) and (9) give us seven equations in seven variables: $P, X, Q, q$, $q^{*}$, e and $\rho$. Thus, the model is fully specified and can be used to study the effects of the changes in costs, the number of firms and other parameters on the endogenous variables.

\section{THE SUPER-ADdITIVITY EFFECT}

According to the super-additivity effect, the probability of a positive finding rises just with cumulation. That is to say, for the same market share, the ex post probability of a positive finding is higher for many small sellers than a few large sellers.

Because the share of the firms subject to the dumping charge, $\beta$, is endogenous in our model, we cannot address the question at hand by changing $\mathrm{n}$ alone. In general, as $\mathrm{n}$ changes, $\beta$ will also change. Therefore, we must assume that in the background, there is at least one parameter that changes by just the right amount to hold $\beta$ fixed. For instance, if the rise in $n$ leads to a rise in $\beta$, we may raise $\mathrm{c}$ by just the right amount to restore $\beta$ to its original value. Under this scenario, we are comparing two industries that are ex post identical in all respects except the number of firms subject to anti-dumping investigation.

At first blush, the proposed comparative statics exercise may seem rather complex. Our task is greatly simplified by two features of the model, however. First, as we demonstrate immediately below, the constancy of market share of one set of firms implies constancy of price and hence total demand. This feature is independent of the linearity of demand and cost functions. Second, the impact of a change in $\mathrm{n}$ on the total expenditure on defense at constant $\beta$ can be derived directly from equation (9).

To proceed with the first of these points, let us use a circumflex $\left(^{\wedge}\right)$ over a variable to denote the proportionate change in that variable. The constancy of market share implies:

$$
\hat{n}+\hat{q}=\hat{X}
$$


Differentiating (2') totally, we have:

$$
\hat{\mathrm{X}}=\alpha_{\mathrm{Q}} \hat{\mathrm{Q}}+\alpha_{\mathrm{q}^{*}} \hat{\mathrm{q}}^{*}+\alpha_{\mathrm{q}}(\hat{\mathrm{n}}+\hat{\mathrm{q}})
$$

where $\alpha$, with appropriate subscript, denotes the market share of the given type of firms. Differentiating equations (1), (4) and (5), respectively, we can obtain:

$$
\begin{aligned}
& \frac{d P}{a-P}=-\hat{X} \\
& \hat{Q}=\frac{d P}{P-C} \\
& \hat{q^{*}}=\frac{d P}{P-c^{*}}
\end{aligned}
$$

Substituting from (10), (13) and (14) into (11), we have:

$$
\left(1-\alpha_{\mathrm{q}}\right) \hat{\mathrm{X}}=\alpha_{\mathrm{Q}} \frac{\mathrm{dP}}{\mathrm{P}-\mathrm{C}}+\alpha_{\mathrm{q}^{*}} \frac{\mathrm{dP}}{\mathrm{P}-\mathrm{c}^{*}}
$$

From (12) and (15), it is immediate that $\mathrm{dP}=0$ and hence $\mathrm{dX}=0$. A fixed market share of a set of firms requires a fixed price and demand as well. Furthermore, given $\mathrm{dX}=0$, equation (10) leads to $\hat{n}=-\hat{q}$.

The super-additivity effect can now be readily derived from equation (9). Differentiating it totally, we obtain:

$$
\beta \rho_{21} \hat{\beta}+\rho_{22} q E \hat{E}+\rho_{2} q \hat{q}=0
$$

Here $\mathrm{E} \equiv$ en denotes the total expenditure on defense by the firms subject to the injury investigation. Setting $\hat{\beta}=0$ and substituting $\hat{n}=-\hat{q}$, we immediately obtain:

(16) $\hat{\mathrm{E}}=\frac{\rho_{2}}{\rho_{22} \mathrm{E}} \hat{\mathrm{n}}$

Remembering $\rho_{2}<0$ and $\rho_{22}>0$, we see that $E$ and $n$ are negatively related. That is to say, an increase in the number of firms is associated with a decrease in the total effort on the part of the defending firms and, hence, an increase in the probability of affirmative finding, just as the empirical evidence shows. 


\section{Concluding Remarks}

In this paper, we have provided a theoretical explanation of the interesting finding of Hansen and Prusa (1996) and Tharakan, Greenaway and Tharakan (1998) that cumulation across many small exporters by itself leads to increased probability of an affirmative determination in injury investigations. For the same import-penetration ratio, the verdict against many small sellers is more likely to be positive than a few large sellers.

In the process of establishing our result, we have also provided the first formal model of injury investigations in anti-dumping cases. A key feature of this model, missing from the existing models of anti-dumping, is the presence of third countries. In our future work, we plan to exploit this feature to study the effects of anti-dumping on "third-country" exporters who are not subject to anti-dumping.

We conclude by noting an alternative explanation of the super-additivity effects suggested by Robert Staiger. According to him, this effect may also arise if the probability of a positive finding rises with the dumping margin. Ceteris paribus, the larger the number of firms exporting to the country in which dumping takes place the more intense is competition and hence lower the price there. As long as this does not impact the price charged by the exporting firms in their domestic markets, we will observe a larger dumping margin and hence a larger probability of positive finding on injury. 


\section{References}

Anderson, J. E., (1993), "Domino Dumping II: Antidumping", Journal of International Economics, Vol. 35, 133-150

Blonigen, B., and S. Haynes, (1999), "Antidumping Investigations and the Pass-Through of Exchange Rates and Antidumping Duties", NBER paper 7378.

Brander, James and Paul Krugman, (1983), "A Reciprocal Dumping Model of International Trade," Journal of International Economics 15, 313-23.

Ethier, W. J., (1982), “Dumping”, Journal of Political Economy 90, 481-506.

Hansen, W. L. and T. J. Prusa, 1996, "Cumulation and ITC Decision-making: The Sum of the parts is Greater Than the Whole", Economic Enquiry, 34, 746-69.

Hillman, A. L., 1989, "The Political Economy of Protection, Fundamentals of Pure and Applied Economics series, vol. 32, International Trade section, chapter 6.

Panagariya, A. and P. Gupta, (1998), "Anti-dumping Duty versus Price Competition," World Economy 21(8), 1998, 1003-1019.

Panagariya, A. and D. Rodrik, 1993, Political Economy Arguments for a Uniform Tariff, International Economic Review, 34, pp 685-703.

Prusa, T. J., 1998, "Cumulation and Anti-dumping", The World Economy, pp 1021-1033.

Rodrik, D., 1986, "Tariffs, Subsidies, and Welfare with Endogenous Policy", Journal of International Economics, 21, 285-299.

Rosendroff, B. P., (1996), "Voluntary Export Restraints, Anti-Dumping Procedures and Domestic Politics", American Economic Review, Vol. 86, No. 3.

Staiger, R. W., and Wolak, F. A., (1992), "The Effect of Domestic Antidumping Law in the Presence of Foreign Monopolist", Journal of International Economics, Vol. 32, 265-287.

Staiger, R.W., and Wolak, F. A., (1994), "Measuring Industry-Specific Protection: Anti-dumping in the United States", Brookings Papers: Microeconomics, 51-118.

Tharakan, P. K. M., D. Greenaway and J. Tharakan, 1998, "Cumulation and Injury Determination of the European Community in Antidumping Cases", Weltwirtschaftliches Archiv, 34, 320-339

Ursprung, H. W., 1990, "Public Goods, Rent Dissipation, and Candidate Competition", Economics and Politics, V2, n2, 115-132. 